ARTICLE

https://doi.org/10.1038/s41467-019-11834-1

\title{
Prebiotic condensation through wet-dry cycling regulated by deliquescence
}

Thomas D. Campbell (1) 1,3, Rio Febrian (D) 1,3, Jack T. McCarthy (1) ${ }^{1}$, Holly E. Kleinschmidt (1) 1, Jay G. Forsythe $\mathbb{1}^{2} \&$ Paul J. Bracher (1) ${ }^{1}$

Wet-dry cycling is widely regarded as a means of driving condensation reactions under prebiotic conditions to generate mixtures of prospective biopolymers. A criticism of this model is its reliance on unpredictable rehydration events, like rainstorms. Here, we report the ability of deliquescent minerals to mediate the oligomerization of glycine during iterative wet-dry cycles. The reaction mixtures evaporate to dryness at high temperatures and spontaneously reacquire water vapor to form aqueous solutions at low temperatures. Deliquescent mixtures can foster yields of oligomerization over ten-fold higher than nondeliquescent controls. The deliquescent mixtures tightly regulate their moisture content, which is crucial, as too little water precludes dissolution of the reactants while too much water favors hydrolysis over condensation. The model also suggests a potential reason why life evolved to favor the enrichment of potassium: so living systems could acquire and retain sufficient water to serve as a solvent for biochemical reactions.

\footnotetext{
${ }^{1}$ Department of Chemistry, Saint Louis University, 3501 Laclede Avenue, St. Louis, Missouri 63103, USA. ${ }^{2}$ Department of Chemistry and Biochemistry, College of Charleston, 66 George Street, Charleston, South Carolina 29424, USA. ${ }^{3}$ These authors contributed equally: Thomas D. Campbell, Rio Febrian. Correspondence and requests for materials should be addressed to P.J.B. (email: paul.bracher@slu.edu)
} 
E lucidating the means by which the first functional biopolymers arose on Earth is a major focus of origin-of-life research ${ }^{1-3}$. Condensation reactions-like the conversion of amino acids into peptides-present a considerable challenge, because the reactions are thermodynamically disfavored in water ${ }^{4,5}$. Wet-dry cycling is commonly viewed as a feasible means of driving condensation reactions in prebiotic conditions to generate mixtures of prospective protobiopolymers, including peptides, depsipeptides, nucleic acids, and others ${ }^{6-16}$. The standard model for wet-dry cycling invokes iterative phases of cool temperatures and rain followed by periods that are hot and dry. The hot and dry phase of each cycle drives the condensation reactions, while the wet phase supplies solvent to permit better diffusion of reactants than is possible in solid mixtures ${ }^{17,18}$. One obvious shortcoming of the model is its reliance on rainstorms or flooding as controlled sources of water. While flooding and runoff are sometimes invoked as advantages in prebiotic scenarios ${ }^{19}$, the challenge of overdilution to cellular compartmentalization is a well-known problem in the origin of life $\mathrm{e}^{20,21}$. Before the existence of enclosed cells protected by membranes or other structures, it is difficult to imagine flooding as anything, but predominantly destructive to protobiotic reaction mixtures.

Deliquescent substances-which form aqueous solutions by absorbing water vapor-offer a solution to the overdilution problem. Deliquescent salts absorb a limited amount of water from the air, based on the relative humidity. A mixture of deliquescent salts would regulate the volume of the system as modern cells have evolved to do 21,22 .

A substance is deliquescent if it spontaneously acquires water vapor from its surrounding atmosphere-at a given temperature and relative humidity (\%RH)-to form a homogeneous aqueous solution 23,24 . As the humidity increases around a potentially deliquescent substance, water vapor adsorbs to the surface until the humidity reaches the critical deliquescent point $\left(\mathrm{RH}_{0}\right)$, where spontaneous dissolution occurs ${ }^{23,24}$. At $\mathrm{RH}_{0}$, the vapor pressure of the newly formed solution is less than the partial pressure of the water vapor in the atmosphere. Mass transfer from the atmosphere to the sample occurs until an equilibrium is reached. The reverse process, efflorescence, occurs when the \% RH value is lower than $\mathrm{RH}_{0}{ }^{23}$. When a substance effloresces, water evaporates from the mixture and the solute crystallizes. $\mathrm{RH}_{0}$ values vary from one substance to another, and when two or more substances are in physical contact or a mixture, deliquescence lowering can occur ${ }^{24}$. For example, a mixture of $\mathrm{KCl}$ and $\mathrm{NaCl}$ deliquesces at lower \% $\mathrm{RH}$ than either of the individual salts ${ }^{25}$.

Deliquescent compounds have been identified in natural geological settings, including systems where deliquescent salts play a role in enabling aqueous liquid mixtures to exist in environments that are otherwise too cold and/or dry to support liquid water. The Don Juan Pond in Antarctica is adjacent to several steepsloped water tracks, which are rich in deliquescent $\mathrm{CaCl}_{2}$. In summertime, meltwaters running through the tracks wash calcium-rich brine into the pond, augmenting water levels that fluctuate seasonally in a body of water that rarely freezes, despite surface temperatures that typically descend to $-50^{\circ} \mathrm{C}$ in winters $^{26}$. In a hyperarid region of Chile's Atacama Desert that is otherwise inhospitable to life, endolithic microbial communities reside in deposits of halite. Their photosynthetic activity spikes when the relative humidity rises above $70 \%$, exceeding the threshold $\mathrm{RH}_{0}$ where their halite environment becomes deliquescent ${ }^{27}$. Deliquescent mixtures of chlorides and perchlorates have been identified on $\mathrm{Mars}^{28}$. These mixtures appear to flow seasonally and have garnered significant interest from astrobiologists as the only extant liquid environments on the surface of the planet ${ }^{29}$.
Motivated by reports of natural deliquescent mixtures existing as liquid solutions in arid environments on Earth and Mars-and recognizing how hydration by deliquescence offers an alternative to the contrived reliance on perfect storms to deliver limited amounts of water at regular intervals in standard wet-dry cycling experiments-we sought to test: (i) whether deliquescence could be an effective method for regulated rehydration of a prebiotically relevant reaction mixture subjected to wet-dry cycling, (ii) whether deliquescent mixtures could serve as effective hosts for cycled condensation reactions, and (iii) whether hydration regulated by deliquescence is advantageous relative to manual addition of water that simulates rain events in typical prebiotic experiments.

Here, we report the ability of mixtures of deliquescent minerals to serve as media for the condensation of amino acids into polypeptides during self-regulated, iterative wet-dry cycling. These reaction mixtures evaporate to dryness at high temperatures and reacquire water vapor from the atmosphere to form aqueous solutions at low temperatures, thereby rehydrating without the addition of water by a rainstorm and avoiding the possibility of destructive overdilution. Ostensibly minor differences-e.g., in ambient humidity or the replacement of $\mathrm{K}^{+}$with $\mathrm{Na}^{+}$counterions-can lead to profound differences in the propensity of samples to absorb water, and hence, large differences in the yields of condensation reactions they host.

\section{Results}

Selection of cycling conditions. When choosing conditions for model prebiotic experiments, it is necessary to balance historical plausibility with experimental convenience. Although an Earth day was shorter at $4 \mathrm{Ga}^{30}$, we selected cycles that lasted $24 \mathrm{~h}$ as a reasonable approximation that was also convenient to monitor over many days. The hot-and-dry phases were set to $100^{\circ} \mathrm{C}$ or $120^{\circ} \mathrm{C}$, temperatures in line with those found in previous studies $^{31,32}$. While several previous studies relied on longer drying times ${ }^{33}$-which generally produce higher yields of condensation-long periods of heat $(>6 \mathrm{~h})$ seem unlikely given the 24-h diurnal cycle on Earth. We therefore limited our heating periods to $4-6 \mathrm{~h}$ per cycle.

For the cool phase of each cycle, the relative humidity (\%RH) was varied from $30-70 \% \mathrm{RH}$. Given the wide range of $\% \mathrm{RH}$ values on modern Earth-from single digits in desert climates to $100 \%$ when raining-these values are both reasonable in a historical context and convenient, as they are easily simulated in the laboratory. Values of \% RH much higher or lower are considerably more difficult for a humidity chamber to maintain with precision.

We maintained the temperature at $40^{\circ} \mathrm{C}$ for the cool phase of the wet-dry cycles. A temperature slightly elevated from room temperature was necessary to ensure that a constant temperature, and relative humidity could be maintained despite daily fluctuations in the ambient conditions of the laboratory, e.g., a particularly warm or humid day. The higher cool temperature seems relevant to early Earth, as there is geological evidence it was generally warmer than today ${ }^{34}$

Selection of model reaction and substrates. We targeted the oligomerization of amino acids into peptides as a model condensation reaction for our study for its obvious relevance to prebiotic chemistry. Glycine is the simplest and most prebiotically relevant amino acid. It is produced in the highest yields in simulated prebiotic syntheses of amino acids ${ }^{2,35-37}$, and a multifactor analysis by Trifonov suggests that glycine was the most prevalent amino acid in the earliest proteins ${ }^{38}$. As a matter of experimental rigor, yields of oligoglycines can be measured quantitatively by liquid chromatography ${ }^{14,39}$. Glycine is the only 
canonical amino acid that produces achiral oligomers, which simplifies their analysis relative to other amino acids. Chromatographic analysis is crucial because the high quantity of salts present greatly complicates quantitative analysis by mass spectrometry (see Supplementary Fig. 30, Supplementary Table 25, and related discussion in the Supplementary Discussion). The results from our experiments are summarized in Supplementary Tables 1 and 2.

Deliquescence regulates reversible and limited hydration. We first examined the hydration of a simple mixture of glycine with $\mathrm{K}^{+}$, $\mathrm{Na}^{+}, \mathrm{Cl}^{-}$, and $\mathrm{OH}^{-}$salts. Chloride salts are the water-soluble minerals most abundant on Earth ${ }^{40}$. Hydroxide was selected as a simple source of base to catalyze condensation, which will proceed less efficiently near neutral $\mathrm{pH}^{14}$. While neither $\mathrm{KCl}$ nor $\mathrm{NaCl}$ are deliquescent by themselves at $70 \% \mathrm{RH}$, a mixture of the two and their hydroxides lowered the critical relative humidity $\left(\mathrm{RH}_{0}\right)$ to the point where the mixture was deliquescent. The reaction mixture used for the initial cycling experiments had a 20:10:1 molar ratio of chlorides:glycine:hydroxides with a 3:1 molar ratio of $\mathrm{Na}^{+}: \mathrm{K}^{+}$(see Supplementary Methods and Supplementary Figs. 2 and 3 ).

Identical samples of $50 \mathrm{mg}$ of the salt mixture in glass scintillation vials were cycled with cooling phases at $40^{\circ} \mathrm{C}$ and three different relative humidities: 30,50 , and $70 \% \mathrm{RH}$. The samples at $70 \% \mathrm{RH}-\mathrm{a}$ value above the critical $\mathrm{RH}_{0}$ of the mixture-collected and lost $\sim 0.05 \mathrm{~g}$ of water per cycle, enough to create homogeneous aqueous solutions during the cool phases. The samples at 30 and $50 \% \mathrm{RH}$-below the critical $\mathrm{RH}$-varied by $<0.01 \mathrm{~g}$ and remained white solids throughout both the hot and cool phases of ten complete cycles. Figure 1 shows the change in mass (corresponding to moisture loss and uptake) over time for the 30 and $70 \% \mathrm{RH}$ samples, demonstrating not only how deliquescence (dependent on the $\mathrm{RH}_{0}$ value) can have a profound influence on the rehydration of identical samples, but also on the precise control of this rehydration in terms of reproducibility and reversibility.

Effects of humidity on yields of oligomerization. Next, we tested the ability of these mixtures of salts to host the condensation of glycine by wet-dry cycling with rehydration mediated by changes in atmospheric humidity. Samples were subjected to ten full 24-h cycles of heating (at $100^{\circ} \mathrm{C}$ or $120^{\circ} \mathrm{C}$ ) and cooling (at 30,50 , or 70 $\% \mathrm{RH}$ and $40^{\circ} \mathrm{C}$ ). For samples subjected to $100^{\circ} \mathrm{C}$, the heating phases lasted $6 \mathrm{~h}$ and the cooling phases lasted $18 \mathrm{~h}$. For samples subjected to $120^{\circ} \mathrm{C}$, the heating phases lasted $4 \mathrm{~h}$ and the cooling phases lasted $20 \mathrm{~h}$.

Figure 2 shows the total yield of glycine oligomers $\left(\mathrm{Gly}_{\geq 2}\right)$ for the six combinations of heating and cooling conditions. Regardless of the temperature of heating, the samples that were deliquescent and formed aqueous solutions during the cooling phase (at $70 \% \mathrm{RH}$ ) produced substantially higher yields than those that were not deliquescent and remained solid throughout the experiment (at 30 and $50 \% \mathrm{RH}$ ). All samples that did not rehydrate due to insufficient humidity for deliquescence produced only limited yields of oligomers, below $2.5 \%$. At $70 \% \mathrm{RH}$, where the mixtures were deliquescent, those subjected to heating at $120^{\circ} \mathrm{C}$ produced higher total yields of oligomer after a lesser number of cycles, but by the end of the experiment (ten cycles), the samples heated at $100^{\circ} \mathrm{C}$ were comparable. Supplementary Figs. 4-9 and Supplementary Tables 4-9 show histograms that track the yields of each oligomer measured at the end of cycles 1 , $2,3,5$, and 10 . There is a clear advantage to periodic rehydration of these samples (at $70 \% \mathrm{RH}$ ) versus remaining dry throughout (at 30 and $50 \% \mathrm{RH}$ ).
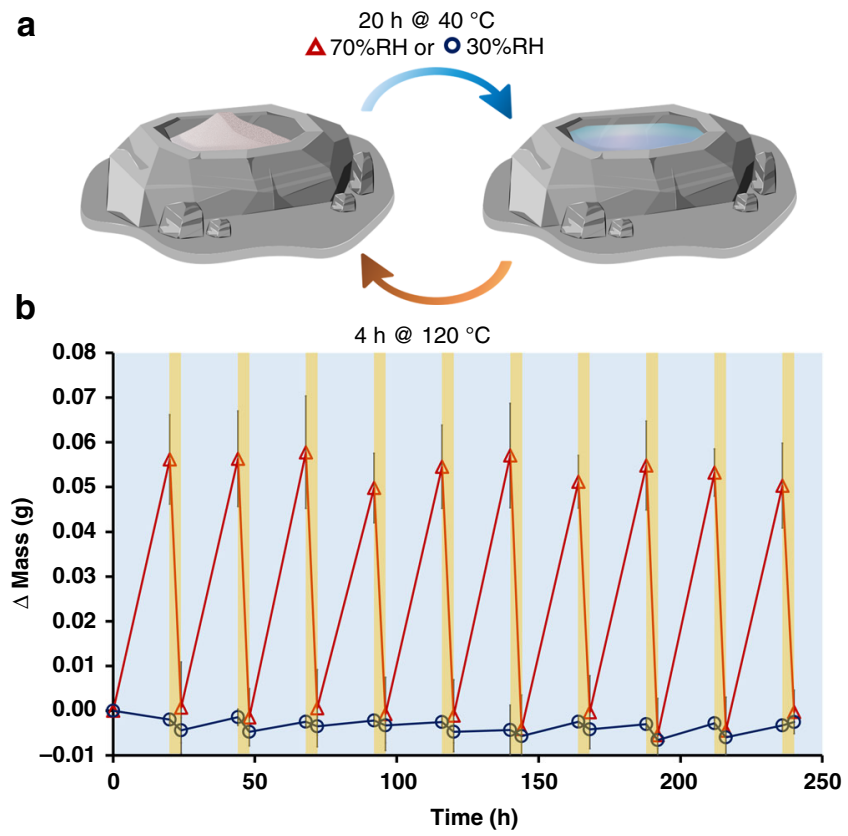

Fig. 1 Demonstration of deliquescent wet-dry cycles. a An illustration of our deliquescent model with its cycling conditions. $\mathbf{b}$ A demonstration of the magnitude, reversibility, and consistency of moisture sorption/desorption during wet-dry cycling of a $50 \mathrm{mg}$ mixture of $\mathrm{K}^{+}, \mathrm{Na}^{+}, \mathrm{Cl}^{-}, \mathrm{OH}^{-}$, and glycine. Containers were weighed over the course of ten complete $24-\mathrm{h}$ cycles to monitor moisture gain and loss at $70 \% \mathrm{RH}$ (red triangles, above $\mathrm{RH}_{0}$ for the mixture) and $30 \% \mathrm{RH}$ (blue circles, below $\mathrm{RH}_{0}$ for the mixture). Each cycle consisted of two phases: a cool phase for $20 \mathrm{~h}$ at $40^{\circ} \mathrm{C}$ (blue background) followed by a hot phase for $4 \mathrm{~h}$ at $120^{\circ} \mathrm{C}$ (orange background). The error bars represent $95 \%$ confidence intervals ( $n=3$ identical experiments). Source data are provided as a Source Data file

In a control experiment, we tested glycine oligomerization starting from homogeneous solutions of the chloride mixtures as opposed to dry mixtures. In these experiments, all of the sample mixtures started as wet in the first cycle before being subjected to cycling with either 30 or $70 \% \mathrm{RH}$ cool periods. We observed that both sets of mixtures gave comparable yields at the end of the first cycle, but the samples cooled at $70 \% \mathrm{RH}$ (such that every cycle had both a wet and a dry phase) gave considerably higher yields for all subsequent cycles versus those cooled at $30 \% \mathrm{RH}$, which dried after the first cycle and remained dry because $\mathrm{RH}_{0}$ was never surpassed (see Supplementary Figs. 12-19 and Supplementary Tables 12-17).

Benefits of regulated rehydration. The results above are consistent with the idea that the increased diffusion of reactants permitted in solution more than compensates for hydrolysis that occurs in the presence of the extra water ${ }^{17,18}$. But there is clearly a limit to the benefits of water in these systems. In an experiment designed to study the effects of overhydration, the same mixtures of glycine with $\mathrm{K}^{+}, \mathrm{Na}^{+}, \mathrm{Cl}^{-}$, and $\mathrm{OH}^{-}$salts were subjected to phases of $6 \mathrm{~h}$ at $100^{\circ} \mathrm{C}$ and $18 \mathrm{~h}$ at $40^{\circ} \mathrm{C}$ and $70 \% \mathrm{RH}$, but at the end of the cooling period, an additional $20 \mathrm{~mL}$ of deionized water was added to a selection of the samples to simulate overhydration. After ten cycles, the samples hydrated by deliquescence alone gave an average total yield of glycine oligomers of $16.0 \%$, while the samples subjected to additional hydration by deionized water gave an average yield of $1.9 \%$ (Fig. 3). The addition of extra water better simulates what would be expected of hydration by rainstorms, which unlike rehydration by deliquescence, cannot be counted on to provide a limited amount of water. The extra water 
a

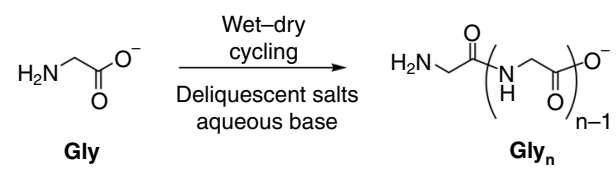

b

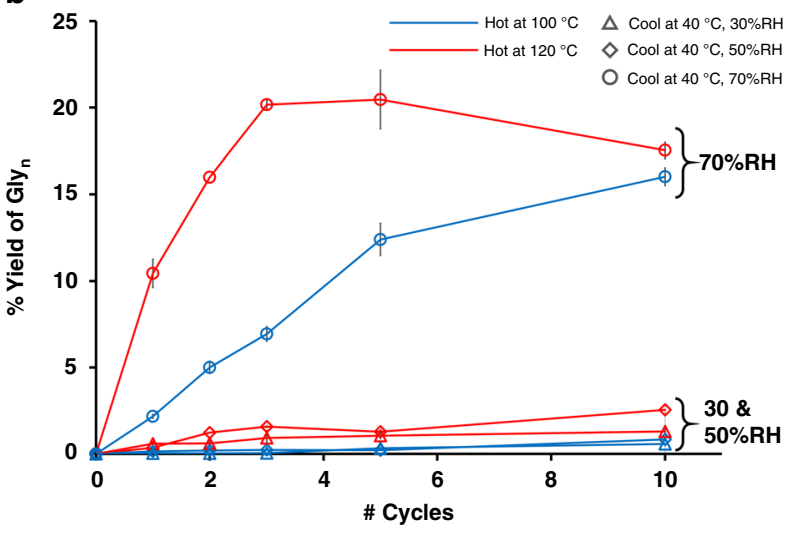

Fig. 2 The condensation of glycine in a deliquescent system. a The condensation of glycine into oligoglycines. We report yields based on the percentage of initial glycine converted into oligomers, excluding cyclic DKP dimer. $\mathbf{b}$ The total yields of glycine oligomers in the presence of $\left(\mathrm{K}^{+} / \mathrm{Na}^{+}\right)$ $\left({ }^{-} \mathrm{Cl} /{ }^{-} \mathrm{OH}\right)$ after $1,2,3,5$, and 10 cycles. Each cycle was $24 \mathrm{~h}$. For the red samples, one cycle included $20 \mathrm{~h}$ at $40{ }^{\circ} \mathrm{C}$ and $70 \% \mathrm{RH}$ (circles), $50 \% \mathrm{RH}$ (diamonds), or $30 \% \mathrm{RH}$ (triangles) followed by $4 \mathrm{~h}$ at $120^{\circ} \mathrm{C}$. For the blue samples, one cycle included $18 \mathrm{~h}$ at $40^{\circ} \mathrm{C}$ and 70,50 or $30 \% \mathrm{RH}$ (circles, diamonds, triangles) followed by $6 \mathrm{~h}$ at $100^{\circ} \mathrm{C}$. The error bars represent $95 \%$ confidence intervals ( $n=3$ identical experiments). The downturn in total yield observed at higher temperature is addressed in the Supplementary Discussion. Source data are provided as a Source Data file

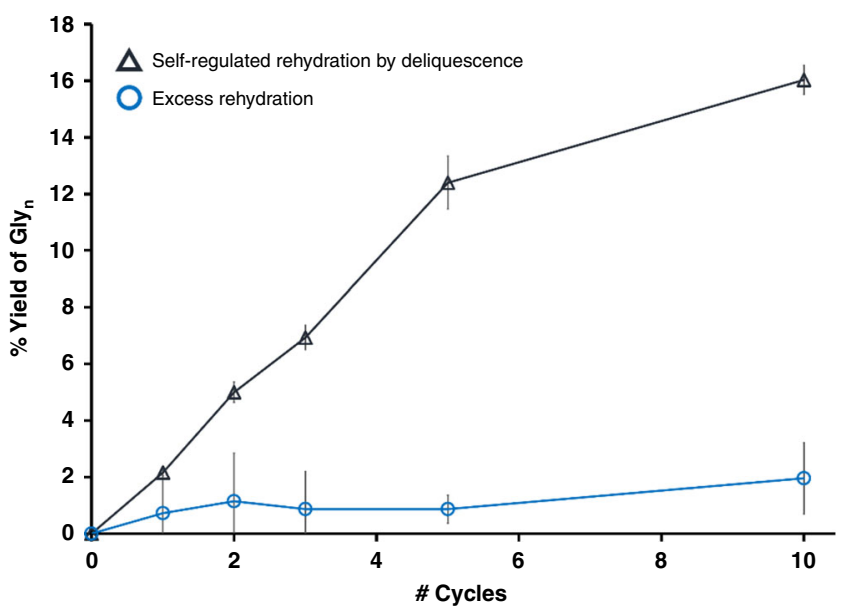

Fig. 3 The advantage of limited rehydration in wet-dry cycling. Yields of glycine oligomers (excluding DKP) in the presence of $\left(\mathrm{K}^{+}, \mathrm{Na}^{+}\right)\left(\mathrm{Cl}^{-}, \mathrm{OH}^{-}\right)$ after 1, 2, 3, 5, and 10 cycles. Each cycle was $24 \mathrm{~h}$. For the samples marked with triangles, one cycle included $18 \mathrm{~h}$ at $40^{\circ} \mathrm{C}$ and $70 \% \mathrm{RH}$, followed by $6 \mathrm{~h}$ at $100^{\circ} \mathrm{C}$. The samples marked with circles were exposed to the same environmental cycles, but $20 \mathrm{~mL}$ of water was added to the mixture before each drying period. This addition simulated heavy rain and overhydration of the sample to verify a shortcoming of the standard model for wet-dry cycling that is obviated by self-regulated, limited rehydration through deliquescence. The error bars represent 95\% confidence intervals $(n=3$ identical experiments). Source data are provided as a Source Data file reduces yields of glycine oligomerization by increasing the duration of time the oligomers are subjected to hydrolysis and decreasing the duration of time in the cycle where condensation is favorable, after the water has evaporated. While the heat and reduced water activity during the evaporative dry phase support peptide synthesis, heat applied to an overhydrated sample-with higher water activity - can favor hydrolysis. The liquid deliquescent brine already had water activity low enough to support peptide condensation, but the evaporation of samples to dryness was critical to the growth of longer oligomers. Control samples of glycine in liquid deliquescent brines heated in capped vials-and hence, not allowed to evaporate-produced trace yields of $\mathrm{Gly}_{2}$ and $\mathrm{Gly}_{3}$ over 10 cycles (1.1\% total), but the yields were comparatively lower than the samples allowed to evaporate to dryness (16.0\% of $\mathrm{Gly}_{\geq 2}$, with up to $\mathrm{Gly}_{13}$ observed, see Supplementary Fig. 31).

Deliquescence controlled by alkali salts. Once we established the efficacy of deliquescence to rehydrate the chloride system, we sought to vary the deliquescent salts used in the mixtures to see if the results of atmospheric rehydration in wet-dry cycling are general. Phosphate salts especially piqued our interest for their importance to biology. At $50 \% \mathrm{RH}, \mathrm{K}_{2} \mathrm{HPO}_{4}$ is deliquescent, while $\mathrm{Na}_{2} \mathrm{HPO}_{4}$ is not. While the availability of phosphate salts was likely limited on the Prebiotic Earth ${ }^{41}$, there is no question that, at some point, phosphate anions became relevant to the development of life $e^{42}$.

In this experiment, rather than vary the relative humidity, we varied the salt. Samples of glycine mixed with $\mathrm{K}_{2} \mathrm{HPO}_{4}$ or $\mathrm{Na}_{2} \mathrm{HPO}_{4}$ were subjected to ten cycles of $20 \mathrm{~h}$ at $40{ }^{\circ} \mathrm{C}$ and $50 \%$ $\mathrm{RH}$ and $4 \mathrm{~h}$ at $120^{\circ} \mathrm{C}$. The results are summarized in Fig. 4. The potassium samples, which were deliquescent and rehydrated completely during the cooling periods, produced total yields of $\mathrm{Gly}_{n}$ of $21.2 \%$. The non-deliquescent sodium samples remained solid through all ten cycles and gave a total yield of Gly ${ }_{n}$ of 3.5\%. Figure $4 \mathrm{~b}$ is a histogram tracking the yield of each oligomer measured at the end of cycles 1, 2, 3, 5, and 10 (see Supplementary Figs. 10, 11 and Supplementary Tables 10, 11 for more details). It is apparent that not only do the total yields improve over time for the deliquescent system, but that the distribution of products favors longer oligomers over time. For the prebiotic condensation of amino acids, this feature is presumably advantageous, as longer oligomers are better suited to developing the secondary and tertiary structure observed in modern functional proteins. Even shorter peptides may have served as functional biomolecules on Prebiotic Earth ${ }^{43-45}$.

In control experiments designed to test whether deliquescence -and not simply potassium itself-is the critical factor responsible for the increased yields of oligomerization, we subjected glycine to wet-dry cycling with $\mathrm{NaBr}$ and $\mathrm{KBr}$. Here, we observed significantly higher yields in the presence of $\mathrm{NaBr}$ versus $\mathrm{KBr}$, which is consistent with the fact that $\mathrm{NaBr}$ is deliquescent and $\mathrm{KBr}$ is not at $50 \% \mathrm{RH}$ (see Supplementary Figs. 23-27 and Supplementary Tables 20-23). However, at $70 \% \mathrm{RH}$, where both the $\mathrm{K}^{+}$and $\mathrm{Na}^{+}$reaction mixtures with glycine are deliquescent, we observed similar yields. Similar to how the deliquescence at $50 \% \mathrm{RH}$ of chloride and bromide salts is reversed for $\mathrm{K}^{+}$and $\mathrm{Na}^{+}, \mathrm{NaH}_{2} \mathrm{PO}_{4}$ is deliquescent and $\mathrm{KH}_{2} \mathrm{PO}_{4}$ is not (reversed relative to the dibasic phosphate salts used above). The condensation of glycine in the deliquescent $\mathrm{NaH}_{2} \mathrm{PO}_{4}$ exceeded $8 \%$ through ten cycles, while the yield in non-deliquescent $\mathrm{KH}_{2} \mathrm{PO}_{4}$ was $0 \%$ (see Supplementary Figs. 20-22 and Supplementary Tables 18, 19). 


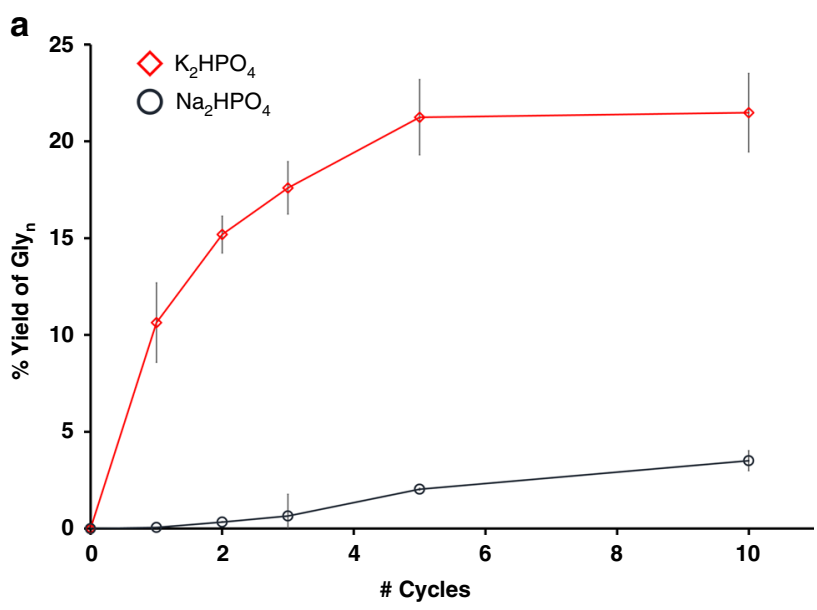

b

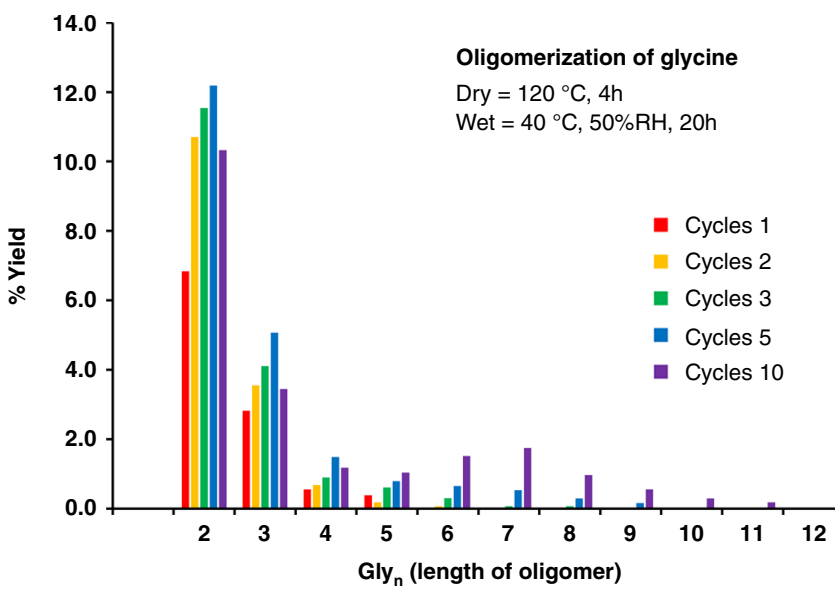

Fig. 4 Glycine oligomerization in $\mathrm{K}_{2} \mathrm{HPO}_{4}$ vs. $\mathrm{Na}_{2} \mathrm{HPO}_{4}$. a The total yields of glycine oligomers (excluding DKP) in the presence of $\mathrm{K}_{2} \mathrm{HPO}_{4}$ (red diamonds) or $\mathrm{Na}_{2} \mathrm{HPO}_{4}$ (blue circles) after 1, 2, 3, 5, and 10 cycles. Each cycle was 24 total hours: $20 \mathrm{~h}$ at $40{ }^{\circ} \mathrm{C}$ and $50 \% \mathrm{RH}$ followed by $4 \mathrm{~h}$ at $120^{\circ} \mathrm{C}$. The error bars represent $95 \%$ confidence intervals $(n=3$ identical experiments). $\mathbf{b}$ Distribution of yields by oligomer length after cycles 1, 2, 3, 5 , and 10 in the sample prepared with $\mathrm{K}_{2} \mathrm{HPO}_{4}$. Source data are provided as a Source Data file

\section{Discussion}

The results for the mixtures that were identical except for the presence of potassium or sodium counterions deserve further discussion. In organic chemistry, $\mathrm{K}^{+}$and $\mathrm{Na}^{+}$are generally viewed as unreactive spectator ions that have little or no significant, specific influence on chemical reactions. However, in the systems reported here, the presence of $\mathrm{K}^{+}$versus $\mathrm{Na}^{+}$has a profound influence on the yield of glycine oligomerization. The fact that $\mathrm{K}_{2} \mathrm{HPO}_{4}$ is deliquescent at $50 \% \mathrm{RH}$, while $\mathrm{Na}_{2} \mathrm{HPO}_{4}$ is not, is responsible for a near tenfold difference in yield.

We briefly surveyed the difference in deliquescence for $\mathrm{K}^{+}$and $\mathrm{Na}^{+}$salts of a variety of counteranions-including halides, carboxylates, carbonates, and phosphates at 30,50 , and $70 \% \mathrm{RH}$ (see Supplementary Fig. 1 and Supplementary Table 3). It was striking that for several of the anions most relevant to biological polymers, $\mathrm{K}^{+}$salts are typically deliquescent while $\mathrm{Na}^{+}$are not. Phosphates are the primary anions associated with nucleic acids, while carboxylates are anions commonly found on proteins. All cells in biology enrich potassium from their external environments, and the vast majority of cells have higher intracellular concentrations of $\mathrm{K}^{+}$than $\mathrm{Na}^{+46-48}$. While no definitive explanation is known for life's universal enrichment of potassium, it is reasonable to consider $\mathrm{K}^{+}$salts may have had a beneficial influence on the regulation of moisture and the solubility of protobiopolymers during life's development. $\mathrm{K}^{+}$may have also supported higher yields in our systems by its modest effect speeding the hydrolysis of DKP to $\mathrm{Gly}_{2}$ and slowing the hydrolysis of Gly $y_{2}$ to Gly (relative to $\left.\mathrm{Na}^{+}\right)^{49}$. We are aware of only one other report of a prebiotic system where swapping $\mathrm{K}^{+}$for $\mathrm{Na}^{+}$resulted in significant differences in yield ${ }^{50}$.

We are particularly interested in what other substrates can undergo condensation to form prospective protobiopolymers, which includes expanding our studies to amino acids other than glycine. We are also interested in surveying other deliquescent minerals for their effects on yields in these systems, including sulfate and carbonate salts, and the influence of water activity ${ }^{51}$. Studies of the kinetics and thermodynamics of condensation and hydrolysis will be of critical importance in any thorough evaluation of these systems. The effects of the inclusion of prebiotically relevant catalysts, such as transition metals and clay minerals, are also of great interest to us. Some clay and salt minerals have been shown to catalyze the formation of potential protobiopolymers and protocellular compartments, including through condensation mediated by wet-dry cycling ${ }^{10,52,53}$. We reiterate that this communication is an initial report of a distinctive system. We will continue to test it, and we encourage others to do so as well.

Wet-dry cycles regulated by natural diurnal oscillations in temperature and humidity - not on uncontrollable rain eventsrepresent an alternative model for driving the prebiotic formation of biopolymers by condensation reactions. Reaction mixtures with naturally deliquescent minerals regulate the extent of their hydration during wet-dry cycling. Above a critical relative humidity, these deliquescent reaction mixtures naturally collect a minimal amount of ambient water vapor to gain the advantages associated with dissolving into aqueous solution without gathering a large excess of water that would drive deleterious hydrolysis reactions. Rehydration mediated by deliquescence offers a model with improved prebiotic relevance, as it avoids the problems of overdilution expected in systems that rely on uncontrolled events, like rainstorms or flooding. The tendency for anions commonly found in modern biopolymers-like phosphates and carboxylates - to have lower critical humidities for deliquescence when paired with $\mathrm{K}^{+}$vs. $\mathrm{Na}^{+}$cations suggests life's preference for potassium may be due, in part, to the regulation of moisture content as life developed and evolved.

\section{Methods}

Cycling experiments. A typical experiment entailed massing the solid salts and glycine, then thoroughly mixing the dry powders using an IKA M20 batch mill. The salts and glycine were mixed in a 2:1 molar ratio (the total moles of salt is twice the moles of glycine at the start of the reaction), and the total mass of the solid mixture stock was $\sim 20 \mathrm{~g}$. For a standard $\left(\mathrm{K}^{+} / \mathrm{Na}^{+}\right)\left({ }^{-} \mathrm{Cl} /{ }^{-} \mathrm{OH}\right)$-glycine stock mixture, we massed $7.00 \mathrm{~g}$ of glycine $(93 \mathrm{mmol}), 3.23 \mathrm{~g}$ of $\mathrm{KCl}(47 \mathrm{mmol}), 8.17 \mathrm{~g}$ of $\mathrm{NaCl}(139 \mathrm{mmol}), 0.13 \mathrm{~g}$ of $\mathrm{KOH}(2.3 \mathrm{mmol})$, and $0.30 \mathrm{~g}$ of $\mathrm{NaOH}(6.9 \mathrm{mmol})$, and transferred the solids into the mill. The mixture was milled for 2 min and transferred to scintillation vials in $50 \mathrm{mg}$ portions. Each reaction was run in triplicate, and each run required five vials per reaction mixture, as one vial was removed for analysis at the end of cycles 1, 2, 3, 5, and 10 (to avoid the problems posed by attempting to sample a potentially heterogeneous solid mixture). For the wet phase of each cycle, the vials were placed in a temperature and humidity-controlled chamber (an FWE Clymate IQ ${ }^{\circledast}$ cabinet) set to $40^{\circ} \mathrm{C}$ and either 30,50 , or $70 \% \mathrm{RH}$. We ensured the precision of these relative humidities by placing independent hygrometers (Fisherbrand ${ }^{\mathrm{Tm}}$ Traceable $^{\mathrm{m} / \mathrm{T}}$ Jumbo Thermo-Humidity Meter) in each of the chambers. Throughout our experiments, the recorded relative humidity stayed within $\pm 5 \%$. For the dry phase of each cycle, the samples were transferred to a hot plate set at $100^{\circ} \mathrm{C}$ or $120^{\circ} \mathrm{C}$ for 6 or $4 \mathrm{~h}$, respectively. As discussed briefly above and in the Supplementary Discussion, there is disagreement in the literature over prebiotic temperatures and length of day, but these conditions seem within the bounds of reason. The samples were analyzed at the conclusion of the drying 
portion of cycles by IP-HPLC and MALDI-TOF MS (see Supplementary Figs. 29, 30 and Supplementary Table 24).

Analytical methods. We have described a method for the quantitative analysis of mixtures of oligoglycine by IP-HPLC ${ }^{39}$. The dry samples from cycling experiments were dissolved in $3.0 \mathrm{~mL} 0.1 \%$ TFA in $\mathrm{H}_{2} \mathrm{O}$ and filtered before analysis by HPLC. The analysis was performed on a Shimadzu LC-20AR fitted with a Phenomenex Luna ${ }^{\oplus}$ C18 column $(250 \times 4.6 \mathrm{~mm}, 3 \mu \mathrm{m}$ particle size $)$. The mobile phase was an aqueous solution of $50 \mathrm{mM} \mathrm{KH}_{2} \mathrm{PO}_{4}$ and $7.2 \mathrm{mM} \mathrm{C}_{6} \mathrm{H}_{13} \mathrm{SO}_{3} \mathrm{Na}$, adjusted to $\mathrm{pH} 2.5$ by the addition of HPLC-grade $85 \% \mathrm{H}_{3} \mathrm{PO}_{4}$. The mobile phase was used isocratically with a flow rate of $1.00 \mathrm{~mL} \mathrm{~min}^{-1}$. The column oven was maintained at $30{ }^{\circ} \mathrm{C}$, and samples were injected in $5.0 \mu \mathrm{L}$ aliquots by autosampler, with detection at $195 \mathrm{~nm}$ and $214 \mathrm{~nm}$. We report individual yields for each oligomer based on the percent glycine converted to that product (see Supplementary Fig. 28 for chromatograms from a typical cycling experiment). The total yield is the sum of the yields of all $\mathrm{Gly}_{n>2}$ products, not including the cyclic dimer of glycine, 2,5-diketopiperazine (DKP). DKP is generally viewed as a prebiotically disadvantageous side product that consumes amino acid building blocks to the detriment of the formation of longer oligomers ${ }^{54,55}$. As reported in previous oligomerizations by Cronin et al., our reaction mixtures generally yellowed over the course of the experiment and some produced insoluble white solids ${ }^{14}$. These solids-presumably, higher $\mathrm{Gly}_{n}$ oligomers insoluble in water-were removed by filtration prior to analysis by HPLC.

Statistics. All experiments were performed in triplicate. Error bars in figures represent 95\% confidence intervals (CIs) based on the $t$ critical values for two-tailed tests. For readability in the text, yields are reported as mean averages without the corresponding CIs.

\section{Data availability}

The data that support the findings of this study are available from the corresponding author upon reasonable request. The raw data underlying Figs. 1-4, Supplementary Figs. 2-28 and 31, and Supplementary Tables 1, 2, and 4-23 are provided as a Source Data file.

Received: 4 March 2019 Accepted: 26 July 2019

Published online: 04 October 2019

\section{References}

1. Danger, G., Plasson, R. \& Pascal, R. Pathways for the formation and evolution of peptides in prebiotic environments. Chem. Soc. Rev. 41, 5416-5429 (2012).

2. Rode, B. M. Peptides and the origin of life. Peptides 20, 773-786 (1999).

3. Sutherland, J. D. The origin of life-out of the blue. Angew. Chem. Int. Ed. 55, 104-121 (2016).

4. Martin, R. B. Free energies and equilibria of peptide bond hydrolysis and formation. Biopolymers 45, 351-353 (1998).

5. Deamer, D. \& Weber, A. L. Bioenergetics and life's origins. Cold Spring Harb. Perspect. Biol. 2, https://doi.org/10.1101/cshperspect.a004929 (2010).

6. Becker, S. et al. Wet-dry cycles enable the parallel origin of canonical and noncanonical nucleosides by continuous synthesis. Nat. Commun. 9, https://doi. org/10.1038/s41467-017-02639-1 (2018).

7. Da Silva, L., Maurel, M. C. \& Deamer, D. Salt-promoted synthesis of RNA-like molecules in simulated hydrothermal conditions. J. Mol. Evol. 80, 86-97 (2015).

8. Forsythe, J. G. et al. Ester-mediated amide bond formation driven by wet-dry cycles: a possible path to polypeptides on the prebiotic Earth. Angew. Chem. Int. Ed. 54, 9871-9875 (2015).

9. Fox, S. W. \& Harada, K. The thermal copolymerization of amino acids common to protein. J. Am. Chem. Soc. 82, 3745-3751 (1960).

10. Lahav, N., White, D. \& Chang, S. Peptide formation in the prebiotic era: thermal condensation of glycine in fluctuating clay environments. Science 201, 67-69 (1978)

11. Mamajanov, I. et al. Ester formation and hydrolysis during wet-dry cycles: generation of far-from-equilibrium polymers in a model prebiotic reaction. Macromolecules 47, 1334-1343 (2014).

12. Nelson, K. E., Robertson, M. P., Levy, M. \& Miller, S. L. Concentration by evaporation and the prebiotic synthesis of cytosine. Orig. Life Evol. Biosph. 31, 221-229 (2001).

13. Rajamani, S. et al. Lipid-assisted synthesis of RNA-like polymers from mononucleotides. Orig. Life Evol. Biosph. 38, 57-74 (2008).

14. Rodriguez-Garcia, M. et al. Formation of oligopeptides in high yield under simple programmable conditions. Nat. Commun. 6, https://doi.org/10.1038/ ncomms9385 (2015).

15. Shen, C., Lazcano, A. \& Oró, J. The enhancement activities of histidylhistidine in some prebiotic reactions. J. Mol. Evol. 31, 445-452 (1990).
16. Fox, S., Pleyer, H. L. \& Strasdeit, H. An automated apparatus for the simulation of prebiotic wet-dry cycles under strictly anaerobic conditions. Int. J. Astrobiol. 18, 60-72 (2019).

17. Higgs, P. G. The effect of limited diffusion and wet-dry cycling on reversible polymerization reactions: implications for prebiotic synthesis of nucleic acids. Life 6, https://doi.org/10.3390/life6020024 (2016).

18. Walker, S. I., Grover, M. A. \& Hud, N. V. Universal sequence replication, reversible polymerization and early functional biopolymers: a model for the initiation of prebiotic sequence evolution. PLoS One 7, e34166 https://doi.org/ 10.1371/journal.pone.0034166 (2012).

19. Patel, B. H., Percivalle, C., Ritson, D. J., Duffy, C. D. \& Sutherland, J. D. Common origins of RNA, protein and lipid precursors in a cyanosulfidic protometabolism. Nat. Chem. 7, 301-307 (2015).

20. Szostak, J. W., Bartel, D. P. \& Luisi, P. L. Synthesizing life. Nature 409 , 387-390 (2001)

21. Monnard, P.-A. \& Walde, P. Current ideas about prebiological compartmentalization. Life 5, 1239-1263 (2015).

22. Lang, F., Ritter, M., Völkl, H. \& Häussinger, D. The biological significance of cell volume. Ren. Physiol. Biochem. 16, 48-65 (1993).

23. Martin, S. T. Phase transitions of aqueous atmospheric particles. Chem. Rev. 100, 3403-3453 (2000).

24. Mauer, L. J. \& Taylor, L. S. Water-solids interactions: deliquescence. In: Doyle M. P., Klaenhammer T. R. (eds). Annual Review of Food Science and Technology, Vol. 1 (eds Doyle, M. P., Klaenhammer, T. R.) 41-63 (Annual Reviews, Palo Alto, 2010).

25. Tang, I. N. \& Munkelwitz, H. R. Composition and temperature dependence of the deliquescence properties of hygroscopic aerosols. Atmos. Environ., Part A 27, 467-473 (1993)

26. Dickson, J. L., Head, J. W., Levy, J. S. \& Marchant, D. R. Don Juan Pond, Antarctica: near-surface $\mathrm{CaCl}_{2}$-brine feeding Earth's most saline lake and implications for Mars. Sci. Rep. 3, https://doi.org/10.1038/srep01166 (2013).

27. Davila, A. F., Hawes, I., Ascaso, C. \& Wierzchos, J. Salt deliquescence drives photosynthesis in the hyperarid Atacama Desert. Environ. Microbiol. Rep. 5, 583-587 (2013)

28. Ojha, L. et al. Spectral evidence for hydrated salts in recurring slope lineae on Mars. Nat. Geosci. 8, 829-832 (2015).

29. Gough, R. V., Chevrier, V. F. \& Tolbert, M. A. Formation of aqueous solutions on Mars via deliquescence of chloride-perchlorate binary mixtures. Earth Planet. Sci. Lett. 393, 73-82 (2014).

30. Varga, P., Rybicki, K. R. \& Denis, C. Comment on the paper "Fast tidal cycling and the origin of life" by Richard Lathe. Icarus 180, 274-276 (2006).

31. Sakata, K., Kitadai, N. \& Yokoyama, T. Effects of $\mathrm{pH}$ and temperature on dimerization rate of glycine: evaluation of favorable environmental conditions for chemical evolution of life. Geochim. Cosmochim. Acta 74, 6841-6851 (2010).

32. Yu, S.-S. et al. Kinetics of prebiotic depsipeptide formation from the ester-amide exchange reaction. Phys. Chem. Chem. Phys. 18, 28441-28450 (2016).

33. Iqubal, M. A., Sharma, R., Jheeta, S. \& Kamaluddin Thermal condensation of glycine and alanine on metal ferrite surface: primitive peptide bond formation scenario. Life 7, https://doi.org/10.3390/life7020015 (2017).

34. Ushikubo, T. et al. Lithium in Jack Hills zircons: evidence for extensive weathering of Earth's earliest crust. Earth Planet. Sci. Lett. 272, 666-676 (2008).

35. Miller, S. L. A production of amino acids under possible primitive earth conditions. Science 117, 528-529 (1953).

36. Miller, S. L. Production of some organic compounds under possible primitive earth conditions. J. Am. Chem. Soc. 77, 2351-2361 (1955).

37. Miller, S. L. The endogenous synthesis of organic compounds. In The Molecular Origins of Life. (ed Brack A) 59-85 (Cambridge University Press, Cambridge, 1998).

38. Trifonov, E. N. The triplet code from first principles. J. Biomol. Struct. Dyn. 22, 1-11 (2004).

39. Campbell, T. D., Febrian, R., Kleinschmidt, H. E., Smith, K. A. \& Bracher, P. J Quantitative analysis of glycine oligomerization by ion-pair chromatography. ACS Omega 4, 12745-12752 (2019).

40. Holland, H. D. The Chemical Evolution of the Atmosphere and Oceans. (Princeton University Press, Princeton, New Jersey 1984).

41. Pasek, M. A., Gull, M. \& Herschy, B. Phosphorylation on the early Earth. Chem. Geol. 475, 149-170 (2017).

42. Westheimer, F. H. Why nature chose phosphate. Science 235, 1173-1178 (1987).

43. Wieczorek, R., Adamala, K., Gasperi, T., Polticelli, F. \& Stano, P. Small and random peptides: an unexplored reservoir of potentially functional primitive organocatalysts. the case of seryl-histidine. Life, 7, https://doi.org/10.3390/ life7020019 (2017). 
44. Maury, C. P. J. Amyloid and the origin of life: self-replicating catalytic amyloids as prebiotic informational and protometabolic entities. Cell Mol. Life Sci. 75, 1499-1507 (2018).

45. Carny, O. \& Gazit, E. A model for the role of short self-assembled peptides in the very early stages of the origin of life. FASEB J. 19, 1051-1055 (2005).

46. Steinbach, H. B. The prevalence of K. Perspect. Biol. Med. 5, 338-355 (1962).

47. Galimov, E. M., Natochin, Y. V., Ryzhenko, B. N. \& Cherkasova, E. V. Chemical composition of the primary aqueous phase of the Earth and origin of life. Geochem. Int. 50, 1048-1068 (2012)

48. Mulkidjanian, A. Y., Bychkov, A. Y., Dibrova, D. V., Galperin, M. Y. \& Koonin, E. V. Origin of first cells at terrestrial, anoxic geothermal fields. Proc. Natl Acad. Sci. USA 109, E821-E830 (2012).

49. Campbell, T. D., Hart, C. A., Febrian, R., Cheneler, M. L. \& Bracher, P. J. The opposite effect of $\mathrm{K}^{+}$and $\mathrm{Na}^{+}$on the hydrolysis of linear and cyclic dipeptides. Tetrahedron Lett. 59, 2264-2267 (2018).

50. Dubina, M. V. et al. Potassium ions are more effective than sodium ions in salt induced peptide formation. Orig. Life Evol. Biosph. 43, 109-117 (2013).

51. Hazen, R. M. Paleomineralogy of the hadean eon: a preliminary species list. Am. J. Sci. 313, 807-843 (2013).

52. Zhou, R. et al. Catalyzed synthesis of zinc clays by prebiotic central metabolites. Sci. Rep. 7, https://doi.org/10.1038/s41598-017-00558-1 (2017).

53. Hanczyc, M. M., Fujikawa, S. M. \& Szostak, J. W. Experimental models of primitive cellular compartments: encapsulation, growth, and division. Science 302, 618-622 (2003).

54. Brack, A., Ehler, K. W. \& Orgel, L. E. N, N'-carbonyldiimidazole-induced diketopiperazine formation in aqueous solution in the presence of adenosine5'-monophosphate. J. Mol. Evol. 8, 307-310 (1976).

55. Weber, A. L. \& Orgel, L. E. The formation of peptides from the $2^{\prime}\left(3^{\prime}\right)$-glycyl ester of a nucleotide. J. Mol. Evol. 11, 189-198 (1978).

\section{Acknowledgements}

This work was jointly supported by the NSF and the NASA Astrobiology Program, under the NSF Center for Chemical Evolution (CHE-1504217). T.D.C. was supported by the NASA Earth \& Space Science Fellowship Program (Award \#80NSSC17K0521). The NSF and Saint Louis University jointly funded the spectrometer used to acquire ICP-OES data through the NSF Major Research Instrumentation Program (Award CHE-1626501). We are particularly grateful to Mathew T. Graham, Prof. Nicholas V. Hud, and Prof. Martha A. Grover for helpful discussions.

\section{Author contributions}

P.J.B. conceived the project. T.D.C., R.F., and P.J.B. designed the wet-dry cycling experiments. T.D.C., R.F., J.T.M., and H.E.K. performed the wet-dry cycling experiments. T.D.C. and R.F. performed the HPLC analysis of samples. J.G.F. designed and conducted the MALDI-TOF experiments. All authors discussed the results and edited the manuscript prepared by T.D.C., R.F., J.G.F., and P.J.B.

\section{Additional information}

Supplementary Information accompanies this paper at https://doi.org/10.1038/s41467 019-11834-1.

Competing interests: The authors declare no competing interests.

Reprints and permission information is available online at http://npg.nature.com/ reprintsandpermissions/

Peer Review Information: Nature Communications thanks Alfonso Davila, Stefan Fox and other anonymous reviewer(s) for their contribution to the peer review of this work. Peer reviewer reports are available.

Publisher's note: Springer Nature remains neutral with regard to jurisdictional claims in published maps and institutional affiliations.

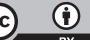

Open Access This article is licensed under a Creative Commons Attribution 4.0 International License, which permits use, sharing, adaptation, distribution and reproduction in any medium or format, as long as you give appropriate credit to the original author(s) and the source, provide a link to the Creative Commons license, and indicate if changes were made. The images or other third party material in this article are included in the article's Creative Commons license, unless indicated otherwise in a credit line to the material. If material is not included in the article's Creative Commons license and your intended use is not permitted by statutory regulation or exceeds the permitted use, you will need to obtain permission directly from the copyright holder. To view a copy of this license, visit http://creativecommons.org/ licenses/by/4.0\%

(C) The Author(s) 2019 